\title{
MEIO AMBIENTE, TRABALHO E SUA INTERFACE NA PROTEÇÃO DO TRABALHADOR FRENTE À EXPOSIÇÃO DE RISCOS DECORRENTES DA MANIPULAÇÃO DE NANOMATERIAIS
}

Flávia de Paiva Medeiros de Oliveira

Doutora em Direito do Trabalho e Previdência Social, pela Universidade de Valencia (Espanha), professora do UNIPE (Centro Universitário de João Pessoa-PB) e da UEPB (Universidade Estadual da Paraíba).

LuCiRa Freire Monteiro

Doutoranda da Universidade de Coimbra, FDUC/CES Programa Direito, Justica e Cidadania no Século XXI, professora da UEPB (Universidade Estadual da Paraíba).

\section{Resumo}

A frequente inclusão de nano materiais na indústria de alimentos, cosméticos e combustíveis inclui riscos à saúde humana que nem sempre são mensurados ou mencionados. A ausência de certeza científica acerca da lesividade ou não de tais substâncias não pode ser utilizada como fator permissivo para que tais materiais sejam manipulados sem o devido estabelecimento de um padrão mínimo de proteção cuja finalidade deve ser sempre resguardar a vida, a saúde e a dignidade da pessoa trabalhadora. Na interface do Direito Ambiental com o Direito do Trabalho, o que se pretende propor é uma reinterpretação do instituto da insalubridade como base para a elaboração de uma norma capaz de garantir salubridade ao meio ambiente de trabalho envolvido com nanopartículas. Em conclusão, considera-se a necessidade da redefinição do papel das entidades sindicais, que deverão se revestir de sua responsabilidade socioambiental para defender a higidez de seus representados, bem como participar de forma efetiva da defesa do meio ambiente externo ao entorno produtivo.

\section{Palavras-chave}

Direito fundamental ao trabalho; Insalubridade; Nano materiais; Meio ambiente; responsabilidade socioambiental.

\section{Resumen}

La frecuente utilización de nanomaterialess en la industria de alimentación, cosméticos, combustibles, causa riesgo a la salud humana que todavía no son conocidos. La 
inexistencia de certeza científica sobre los posibles males que tales partículas generan no puede ser utilizada como un factor de permisividad para que estos materiales sean manipulados sin la observancia de un grado mínimo de protección cuya finalidad deberá ser siempre la tutela de la vida, salud y dignidad del trabajador. En el intercambio entre el Derecho Ambiental y el Derecho del Trabajo, lo que se pretende proponer es una nueva interpretación del instituto jurídico de la insalubridad como fundamento para la elaboración de una norma capaz de garantizar la salubridad del ambiente de trabajo en lo cual se utiliza partículas nano. A título de conclusión, también la necesidad de redefinición del papel de los sindicatos, que deberán cumplir su responsabilidad socio ambiental para promocionar y defender la salud de sus trabajadores y además participar efectivamente de la tutela del ambiente externo al entorno productivo.

\section{Palabras clave}

Derecho fundamental al trabajo; Insalubridad; Nanomateriales; Medio ambiente; Responsabilidad socio ambiental.

\section{Introdução}

A concepçáo do meio ambiente como um bem de natureza holística leva obrigatoriamente a necessidade de encará-lo como algo que vai além da proteção da fauna e da flora e a vê-lo de forma integrada, pelo conjunto de todos os bens que permitem à vida em condiçóes dignas. Essa nova ideia fortalece a necessidade de definir critérios e padróes suscetíveis de instituir uma ecotecnologia capaz, inclusive, de minimizar os impactos do desenvolvimento tecnológico sobre aqueles que lidam, de forma direta ou indireta com essas mudanças.

Nesse cenário, um problema que, ainda não se tornou socialmente relevante, especialmente no âmbito do Direito brasileiro, mas que já é uma inequívoca realidade do ponto de vista do Direito europeu éo uso de nanomateriais, sobretudo, na indústria cosmética, de alimentos e de combustíveis. Essa utilização passa despercebida da sociedade em geral, porque são poucos os estudos científicos sobre os riscos que essas substâncias causam para a saúde em geral, inviabilizando uma divulgaçáo segura sobre consequências ambientais da sua utilização.

A falta de tais estudos e, por conseguinte, a ausência de certeza científica sobre os danos, gera a ideia, também destituída de comprovação científica, de que essa tecnologia traz mais benefícios do que malefícios aos seus consumidores ou e pouco ou nenhum aos trabalhadores nesse setor. Com base nessa ideia e na incerteza que ora impera, é que se tem na legislação interna um vazio normativo, seja na reinterpretação dos institutos existentes, seja na elaboração de um marco normativo que aborde a questão de forma específica. 
Por essa razão, partindo-se da interface entre o Direito Ambiental e o Direito do Trabalho é que se pretende propor com este artigo uma reinterpretação do instituto da insalubridade e lançar as bases que poderão servir de norte para elaboração de uma norma interna capaz de afrontar a situaçáo de forma eficiente para garantir a salubridade do meio ambiente de trabalho daqueles trabalhadores que lidam diretamente com nanopartículas, através, sobretudo, de uma redefinição do papel das entidades sindicais, que deverão se revestir de sua responsabilidade socioambiental para defender a higidez de seus representados, bem como participar de forma efetiva da defesa do meio ambiente externo ao entorno produtivo.

\section{O Meio Ambiente e a Necessidade de Proteção do Trabalhador Decorrente dos Riscos Derivados da Manipulação de Nanomateriais}

A Lei no 6.938/1981 regulou a Política Nacional do Meio Ambiente e trouxe uma definição operacional de meio ambiente, considerando um "conjunto de condiçôes, leis, influências e interaçóes de ordem física, química e biológica, que permite, abriga e rege a vida em todas as suas formas (art. $\left.3^{\circ}, \mathrm{I}\right)$ ”.

Essa concepção assim abrangente parte de uma visão holística do meio ambiente, já que esse bem passa a ser analisado de forma integral e merecendo proteção a totalidade de tudo aquilo que permite a vida (BOFF, 1993, p. 17). Essa percepção integral muda o foco da tutela, que, antes da referida lei e da Constituição vigente centrava-se nos recursos naturais, limitando o objeto de defesa a outros bens, inclusive, de natureza imaterial, mas insuficientes na configuraçãoda vida em todas as suas formas.

A necessidade de proteção do meio ambiente não pode não pode ser vista como um objeto específico. Ele apresenta interdependência e inter-relação com outros elementos. Nesse sentido, é possível dizer que, tanto a mencionada Lei, quanto a Carta Constitucional atual, instituíram uma concepção desse bem jurídico como macrobem, de modo que ele não se confunde com este ou com aquele bem corpóreo que o forma (LEITE, 1998, p. 59).

Ao contrário, caracteriza-se por interagir no conjunto de todos os elementos que propiciam a vida em todas as suas formas. Todos aqueles bens reunidos vão compor uma individualidade própria e autônoma que não se confunde com as suas partes integrantes e que na dicção do artigo 225, da Constituição Federal de1988, torna-se "essencial à sadia qualidade de vida”. A questão ambiental é algo que diz respeito à própria vida e a todos os elementos que são indispensáveis para a sua boa qualidade, sejam eles naturais, culturais ou artificiais.

Assim, Leff (2002, p.160) assevera que:

"O ambiente não é o meio que circunda as espécies e as populações biológicas; é uma categoria sociológica (e não biológica), relativa a uma 
racionalidade social, configurada por comportamentos, valores e saberes, bem como por novos potenciais produtivos.

(...)

$\mathrm{O}$ ambiente estabelece potenciais e limites às formas e ritmos de exploração dos recursos, condicionando os processos de valorização, acumulação e reprodução do capital."

O meio ambiente deixa, destarte, de ter um cunho eminentemente natural e passa a ser encarado como uma realidade social e cotidiana da vida do ser humano em todos os espaços sociais no quais ele é chamado a interagir.

Por essa razão, Boff (1993, p. 25) propugna que é imperioso criar "uma cultura ecológica, com comportamentos e práticas incorporados na visão de mundo e que têm como efeito mais suavidade e benevolência na relação para com a natureza”. Defende, ainda, o desenvolvimento deeco tecnologia, por meio da qual sejamadotados técnicas e procedimentos que visem à preservação do meio ambiente e a amenização dos efeitos negativos não desejados sobre a classe trabalhadora e as naçóes mais pobres.

Nesse cenário, surge uma preocupação recente, que, todavia, passa despercebida da população em geral, que diz respeito ao uso de nanomateriais de forma cada vez mais frequente, sobretudo, nas indústrias de alimentos, cosméticos e combustíveis e os riscos que esse tipo de tecnologia pode causar para a saúde humana. Os países europeus têm feito um grande esforço para elaborar uma definição normativa para esses novos materiais, a fim de, partindo dela, estabelecer um padrão de proteção que possa ser utilizado pelos países membros da União.

Assim sendo, a Recomendação 2011/696 da Comissão, de 20 de outubro de 2011 (COMISSÃO EUROPEIA, 2011) ${ }^{1}$,propôs o seguinte:

"nanomaterial como um material natural, incidental ou fabricado, que contém partículas num estado desagregado ou na forma de um agregado ou de um aglomerado, e em cuja distribuição número-tamanho $50 \%$ ou mais das partículas têm uma ou mais dimensốes externas na gama de tamanhos compreendidos entre $1 \mathrm{~nm}$ e $100 \mathrm{~nm}$. Em casos específicos e sempre que tal se justifique devido a preocupações ambientais e ligadas à saúde, segurança e competitividade, o limiar da distribuição númerotamanho de $50 \%$ pode ser substituído por um limiar compreendido entre 1 e $50 \%$. [...]"

A União Europeia identificou também a nanotecnologia como uma tecnologia facilitadora essencial (TFE) que fornece a base para uma maior inovação e novos produtos,

1 Disponível em: http://eurlex.europa.eu/LexUriServ/LexUriServ.do?uri=OJ:L:2011:275:0038:0040:PT:PDF 
já tendo delineado uma estratégia única para as TFE, incluindo as nanotecnologias, com base em três pilares: a investigação tecnológica, a demonstração de produtos e as atividades de fabrico competitivas ${ }^{2}$.

As consequências dos nanomateriais para a saúde humana, ainda, não podem ser determinadas com precisão científica. Essa incerteza também existe acerca dos efeitos adversos para os trabalhadores que lidam diretamente com ele. Esse fator é ainda mais agravado pelo dinamismo com que surgem novos materiais e substâncias químicas suscetíveis de serem manipulados em dimensôes cada vez menores.

Em 2008, havia no banco de dados do CAS (Chemical Abstract Service) uma divisão da ACS (American ChemicalSociety) de 36.660.377 compostos orgânicos e inorgânicos, dos quais 21.867 .815 eram compostos químicos disponíveis comercialmente. Em 2013, esse número passou a ser de mais de 72.841 .808 compostos e substâncias registradas, um acréscimo de quase $100 \%$ (cem por cento) em um período de apenas 5 (cinco) anos. Todavia, o guia de valores de exposição ocupacional, publicado em 2013, e compilado pela American ConferenceofGovernmental IndustrialHygienists - ACGIH, apresenta somente 800 (oitocentas) substâncias químicas e a Norma Regulamentadora (NR) no15, do Ministério de Trabalho e Emprego, apenas 147 substâncias são listadas (LENZ E SILVA; LENZ E SILVA, 2013, p. 44).

Esses dados mostram que a utilização de nanomateriais na vida cotidiana do indivíduo pode se mostrar cada vez mais presente, sem que, nem mesmo ele saiba, como também o trabalhador que, ao manipular substâncias químicas, não sabe que se trata de materiais nanométricos. Para exemplificar a complexidade desse assunto, é necessário citar o caso do nanomateriais de carbono, entre eles os nanotubos e as nanofibras de carbono, cujos estudos no ano de 2007 indicavam sua toxicidade biológica decorrente dos metais utilizados no seu processo de síntese. Porém, somente em 2013 a NIOSH (The NationalInstitute for OccupationalSafetyand Health), chegou à conclusão de que tais materiais oferece riscos ocupacional, pelo que é imperioso estabelecer mecanismos de controle de exposição, mediçóes ambientais/laborais, vigilância médica e monitoramento da concentração desse materiais no ambiente de trabalho (LENZ E SILVA; LENZ E SILVA, 2013, p. 45).

Essas informaçóes servem para demonstrar que há necessidade de adequar as normas jurídicas laborais a essa realidade de incerteza, com vistas a evitar que a exposição reiterada do trabalhador a tais substâncias cause prejuízos à sua saúde. A ausência de certeza

2 COMUNICAÇÃO DA COMISSÃO AO PARLAMENTO EUROPEU, AO CONSELHO E AO COMITÉ ECONÓMICO E SOCIAL EUROPEU Segunda revisão regulamentar relativa a «nanomateriais» (Texto relevante para efeitos do EEE), disponível em http://ec.europa.eu/research/industrial_technologies/pdf/policy/communication-from-the-commission-second-regulatory-review-on-nanomaterials_pt.pdf, p. 3-4. 
científica acerca da lesividade ou não de tais substâncias não pode ser utilizada como fator permissivo para que tais materiais sejam manipulados sem o devido estabelecimento de um padrão mínimo de proteção cuja finalidade deve ser sempre resguardar a vida, a saúde e a dignidade da pessoa trabalhadora.

Nesse sentido, a doutrina já entende que:

\footnotetext{
"Nesse ponto, a adoção de novas estratégias na área de segurança ocupacional e meio ambiente, especialmente na análise de riscos e no entendimento dos processos e interaçóes dos nanomateriais no ambiente de trabalho, é essencial para o desenvolvimento de uma nanotecnologia mais segura do pontos de vista laboral.” (LENZ E SILVA; LENZ E SILVA, 2013, p. 45).
}

A imprescindibilidadede padrôes de proteção mínimos para o trabalhador que lida com tais materiais decorre de uma imposição constitucional, na medida em que o art. 7o, XII e XXII da CF/1988, reconhece como fundamental o direito do trabalhador a ser protegido frente aos riscos laborais, impondo a reduçáo dos riscos do trabalho por meio de normas de saúde, higiene e segurança. Nesse mesmo sentido, a sustentaçáo para uma maior proteção do trabalhador está no artigo $1^{\circ}$, III, que alça o valor dignidade da pessoa humana à posição de princípio fundamental do Estado Democrático de Direito brasileiro, além de sero próprio sentido da República Federativa do Brasil. Com esse arcabouço constitucional jamais se poderá utilizar a falta de certeza científica como critério determinante para analisar as atuais normas laborais existentes à luz de uma necessidade de proteção da pessoa trabalhadora frente à exposição a tais riscos.

\section{O Princípio da Precaução como Norteador da Defesa do Trabalhador no Ambiente de Trabalho no Caso dos Nanomateriais}

A ausência de estudos sobre a interação da aplicação das nanotecnologias com o meio ambiente e sobre os riscos em relação aos seres humanos fazem com que se tenha uma ideia de que os benefícios da nanotecnologia se sobrepóem aos seus possíveis efeitos deletérios. No entanto, essa ideia pode não ser real, uma vez que carece de qualquer comprovação científica.

Tal ideia proveniente, sobretudo, do inexistência de estudos científicos sobre os riscos não pode ser considerada como fator excludente da ausência de risco. Pesquisas demonstram que camundongos que receberam nanotubos de carbono desenvolveram lesôes biológicas semelhantes àquelas provocadas pela inalação do amianto (ENGELMANN, 2010 a, p. 255).

Nesse cenário, em que há mais perguntas do que respostas, ganha destaque o princípio da precaução, segundo o qual, havendo incerteza científica em torno das consequências 
que determinada atividade ou tecnologia pode trazer para o meio ambiente e, por conseguinte, para saúde humana, a cautela deve ser o critério utilizado como diretriz para nortear as condutas (HOHENDORFF; ENGELMANN; OSHIRO, 2013, p. 672).

A adoção do princípio mencionado às nanotecnologias impóe a utilização de critérios de razoabilidade e proporcionalidade, a fim de evitar que o temor sobre os possíveis efeitos deletérios ao meio ambiente e à saúde humana sejam utilizados como fator impeditivo para o uso desses materiais. Ao contrário, o que se pretende é que haja um desenvolvimento contínuo das pesquisas com vistas a se chegar a um padráo de certeza científica sobre esses riscos para que se possa estabelecer níveis de proteção confiáveis.

Nesse contexto, o direito e, mais especificamente, o direito ambiental do trabalho, ganham sobrada importância para que essa proporcionalidade ganhe aplicabilidade prática. Por essa razão, a aplicação do princípio da proteção, sob a ótica ecotecnológica, proposta por Boff (1993, p.25), recomenda a não exposição do trabalhador a tais agentes (ENGELMANN; FLORES; WEYERMÜLLER, 2010, p. 208), o que, por conseguinte, implica a adoçáo de medidas protetivas no ambiente de trabalho capazes de proteger a derme e o sistema ocular, de evitar a ingestâo de nanopartículas, de proteger contra explosôes e incêndios(LENZ E SILVA, 2013, p. 46-49).

Essas medidas devem ter como finalidade evitar, totalmente, a exposiçáo do trabalhador ao risco, o que somente pode se efetivar com uma análise detalhada dos riscos envolvidos na produção, estocagem, incorporação, uso e descarte dos nanomateriais. Quando se trata de empreendimentos novos, um grande aliado para a determinação desses riscos de forma mais segura, são os estudos ambientais com especial destaque para a Análise Preliminar de Risco (APR), prevista pelo art. 1º, III, da Resolução Conama no 237/1997. Estaé tida, pelos profissionais da área de segurança do trabalho, como um estudo antecipado e detalhado de todas as fases do trabalho, a fim de detectar os possíveis problemas que poderão acontecer durante a sua execução, para que se adotem as medidas necessárias a sua neutralização, criando, assim, um ambiente de trabalho seguro.

De acordo com a norma mencionada, esse estudo é um dos que poderá ser exigido pelo órgão responsável pelo licenciamento ambiental como requisito para a concessão da licença de empreendimentos que lidem com a manipulação de nanomateriais.

\section{A Necessidade de Elaboração de um Marco Regulatório Acerca da Prote- ção da Saúde do Trabalhador em Face do Labor com Nanomateriais}

A incerteza científica sobre os riscos do uso de nanomateriais, tanto para a sociedade em geral, como para aqueles que lidam diariamente com essa nova tecnologia como ferramenta de trabalho, não pode funcionar como uma desculpa para deixar de tentar oferecer uma possível saída jurídica para o problema. 
Nas discussôes técnicas levantadas em torno tema no Brasil, pode-se afirmar que existe uma tendência a deixar de enfrentar o problema legalmente. Todavia, cumpre procurar uma solução para a situação, seja uma mais imediata, com a reformulação de institutos jurídicos já existentes no ordenamento atual, seja por meio da busca de parâmetros capazes de fornecer as bases para um tratamento específico e mais abrangente sobre a questão.

Desse modo, a abordagem cabível para a questão é, em primeiro lugar, o enfrentamento da matéria no âmbito legislativo, a par do que foi feito na União Europeia, para composição demarco legal. Isto possibilitará um aparato jurídico adequado à problemática brasileira. Em segundo, que se proceda a uma análise sobre os institutos jurídicos do direito local que podem ser reinterpretados para garantir uma proteção mais eficiente da saúde do trabalhador que lida com os materiais em escala nanomêtricas. Por fim, serão fornecidos alguns elementos que poderão servir ao legislador brasileiro na hora de regular os nanomateriais no ambiente de trabalho.

\subsection{A Proteção Frente aos Nanomateriais no Âmbito da União Europeia}

A proteção aos trabalhadores que lidam com as nanotecnologias na União Europeia tem como ponto de partida, em primeiro lugar, uma norma genérica, a Diretiva 89/391/ CEE do Conselho, de 12 de junho de 1989 (CONSELHO DA UNIÃO EUROPEIA, 1989), que estabeleceu medidas destinadas a promover a melhoria da segurança e da saúde dos trabalhadores, prevendo princípios gerais para a proteção e a prevenção de riscos profissionais e a eliminação dos fatores de acidente, aplicando-se a todos os setores de atividade, tanto os públicos, quanto os privados.

De acordo com o previsto nos artigo $5^{\circ}$, no 1 , e $6^{\circ}$, no 3 , da citada norma, a entidade patronal se encontra obrigada a garantir a "segurança e a saúde dos trabalhadores em todos os aspectos relacionados com o trabalho", como também, dependendo do tipo de atividade empreendida, obriga-se a "avaliar os riscos para a segurança e a saúde dos trabalhadores, inclusive, na escolha dos equipamentos de trabalho e das substâncias ou preparados químicos e na concepção dos locais de trabalho".

A referida diretiva prevê, ainda, que as medidas protetivas no ambiente de trabalho devem ser fundadas no princípio da prevenção, devendo-se evitar, sempre que possível, os aludidos riscos, substituindo o que é perigoso pelo que é isente de perigo ou menos perigoso. Ademais disso, e o mais importante, é que a mencionada disposição prevê a obrigatória consulta aos trabalhadores ou seus representantes sobre as consequências para a sua saúde e segurança sempre que o empresário pretender introduzir o uso de novas tecnologias no processo produtivo.

A Diretiva 1999/92/CE do Parlamento Europeu e do Conselho, de 16 de dezembro de 1999 (PARLAMENTO EUROPEU E CONSELHO, 1999), cria um padrão normativo 
destinado a promover a proteção da segurança e da saúde dos trabalhadores susceptíveis de serem expostos a riscos derivados de atmosfera explosivas. Ela obriga às empresas a procederem à avalição dos riscos de explosão e a adotarem as medidas necessárias para que "os locais onde se formem atmosferas explosivas em concentraçóes suscetíveis de colocar em perigo a saúde e segurança dos trabalhadores ou de terceiros sejam concebidos de modo a que o trabalho possa ser executado em segurança." (art. 5º).

A observância das prescriçóes mínimas contidas na referenciada disposição é muito relevante para o trabalhador que lida com nanopartículas, já que elas podem criar essa atmosfera explosiva, impondo-se ao empreendedor a adotar padróes de segurança que náo coloquem em risco, nem a vida do trabalhador, nem a de terceiros.

A Diretiva 2004/37/CE do Parlamento Europeu e do Conselho, de 29 de abril de 2004 (PARLAMENTO EUROPEU E CONSELHO, 2004), estatui preceitos para a proteção dos trabalhadores contra riscos ligados à exposição a agentes cancerígenos ou mutagênicos durante o labor. Essa prescrição fixa os valores limites de concentração de um agente cancerígeno ou mutagênico no ar respirado pelos trabalhadores. No caso de inalação de nanopartículas, que possam ser configuradas como cancerígenas ou mutagênicas, mister se faz que os valores definidos no Anexo III sejam adaptados.

Outra importante norma europeia sobre o assunto é a Diretiva 2009/104/CE do Parlamento Europeu e do Conselho, de 16 de setembro de 2009 (PARLAMENTO EUROPEU E CONSELHO, 2009), que no artigo $3^{\circ}$, no 1 e 2 , tratou de prescrever critérios mínimos de segurança e de saúde para a utilização pelos trabalhadores dos equipamentos de trabalho, criando para a entidade patronal a obrigação de, no momento de escolher os equipamentos de proteção, "ter em atenção as condiçôes e características específicas do trabalho e dos riscos existentes na empresa ou no estabelecimento, nomeadamente nos postos de trabalho, para a segurança e a saúde dos trabalhadores”.

A Recomendação 2011/696/EU da Comissão, de 20 de outubro de 2011 (COMISSÃO EUROPEIA, 2011), introduziu uma definiçãa de nanomateriais, considerando como tal:

"um material natural, incidental ou fabricado, que contém partículas num estado desagregado ou na forma de um agregado ou de um aglomerado, e em cuja distribuição número-tamanho $50 \%$ ou mais das partículas têm uma ou mais dimensóes externas na gama de tamanhos compreendidos entre $1 \mathrm{~nm}$ e $100 \mathrm{~nm}$. Em casos específicos e sempre que tal se justifique devido a preocupaçóes ambientais e ligadas à saúde, segurança e competitividade, o limiar da distribuição número-tamanho de $50 \%$ pode ser substituído por um limiar compreendido entre 1 e $50 \%$. [...] $]^{\text {33 }}$

3 COMUNiCAÇÃO DA COMISSÁO AO PARLAMENTO EUROPEU, AO CONSELHO E AO COMITÉ ECONÓMICO E SOCIAL EUROPEU Segunda revisão regulamentar relativa a 
Essa definição se destina a ser utilizada pelos Estados-Membros, pelas agências e empresas da União Europeia na elaboração de suas normas internas, a fim de permitirem uma abordagem coerente sobre o tema. Além disso, a própria Comissão deve utilizá-la na legislação da União e nos instrumentos de aplicação, se for necessário.

O que se observa é que, embora as regras anteriores a 2011, não tratem especificamente da proteção do trabalhador frente à nanotecnologia, há um corpo normativo mais específico com relação a determinadas a substâncias ou ambiente de trabalho próprio, o que permite uma maior adaptabilidade dessas disposiçóes à situaçáo nova de uso de nanomateriais no cotidiano do trabalhador.

Ademais, a Uniấo Europeia tem feito esforços para estudar o assunto e desde 2004, o Comité Científico dos Riscos para a Saúde Emergentes e Recentemente Identificados (CCRSERI) e o Comité Científico da Segurança dos Consumidores (CCSC), a Autoridade Europeia para a Segurança dos Alimentos (AESA) e a Agência Europeia de Medicamentos (AEM) têm trabalhadopara avaliação os riscos decorrentes do uso de nanomateriais.

Em 2009, o CCRSERI concluiu que:

apesar de as metodologias de avaliação dos riscos, paraa avaliação dos riscos potenciais das substâncias e das matérias convencionais para ohomem e para o ambiente, serem amplamente utilizadas e serem geralmente aplicáveis aosnanomateriais, os aspetos específicos relativos aos nanomateriais ainda carecem de maiordesenvolvimento. Esta situação manter-se-á até haver informaçôes científicas suficientesdisponíveis para caracterizar os efeitos nocivos dos nanomateriais nos seres humanos e noambiente ${ }^{4}$.

No cenário europeu os esforços para dar ao tema um tratamento único são contínuos e, naquilo que diz respeito diretamente ao ambiente de trabalho, um subgrupo nano do grupo de trabalho sobre produtos químicos, criado pelo Comité Consultivo para a Segurança e a Saúde no Local de Trabalho está preparando um projeto de parecer sobre a avaliação e gestão dos riscos dos nanomateriais no local de trabalho, para ser posteriormente aprovado pelo Comité Consultivo. Pretendia-se, até 2014, ser efetuada uma avaliação final sobre uma revisão da legislação sobre saúde e segurança no trabalho em função destas atividades com as suas respetivas conclusóes.

«nanomateriais» (Texto relevante para efeitos do EEE), disponível em http://ec.europa.eu/research/ industrial_technologies/pdf/policy/communication-from-the-commission-second-regulatory-reviewon-nanomaterials_pt.pdf, p. 2.

4 COMUNICAÇÃO DA COMISSÃO AO PARLAMENTO EUROPEU, AO CONSELHO E AO COMITÉ ECONÓMICO E SOCIAL EUROPEU Segunda revisão regulamentar relativa a «nanomateriais» (Texto relevante para efeitos do EEE), disponível em http://ec.europa.eu/research/ industrial_technologies/pdf/policy/communication-from-the-commission-second-regulatory-reviewon-nanomaterials_pt.pdf, p. 4. 


\subsection{A Atividade Laboral com Nano Materiais e a Configuração do Direito a Adi- cional por Insalubridade}

Existe uma incerteza sobre os riscos dos nanomateriais para a saúde humana, sobretudo, a saúde do trabalhador que lida com esse tipo de material de forma cotidiana e contínua. Por essa razão, é importante indagar se é possível caracterizar esse tipo de material como agente insalubre apto a ensejar o pagamento do adicional de insalubridade ao trabalhador que labora com ele.

O direito ao recebimento do adicional de insalubridade surge quando o empregado é exposto a agentes nocivos a sua saúde, seja pela natureza, condiçóes ou métodos de trabalho, acima dos limites de tolerância fixados em lei (art. 189, da CLT). Convém, ainda, esclarecer que a obrigação do empregador é neutralizar ou eliminar a insalubridade por meio da utilização de equipamentos de proteção individual (art. 191, CLT), de modo que o pagamento do adicional somente surgirá quando os riscos existentes no ambiente insalubre não forem eliminados.

O reconhecimento do direito ao recebimento do adicional de insalubridade demanda o cumprimento de alguns requisitos, a saber: a) a realização de perícia por profissional qualificado, a fim de constatar que o grau de exposição do trabalhador ao agente é superior aos limites de tolerância permitidos; b) o enquadramento legal do agente insalubre em um dos anexos da Norma Regulamentadora (NR) no 15, do Ministério de Trabalho e Emprego; c) inexistência de alguma condição que elimine a insalubridade.

Quando se analisam os requisitos necessários para a configuração da insalubridade, relacionando-os com a manipulação de nanomateriais, surgem alguns problemas. $\mathrm{O}$ primeiro deles diz respeito a ausência de certeza científica sobre os riscos que tais substâncias causam à saúde humana, o que funciona como um critério capaz de dificultar a avaliação pericial. O segundo concerne ao enquadramento legal.

A NR/MTE no 15 lista apenas 147 substâncias insalubres, de maneira que, facilmente, os materiais manométricos ficariam fora dessa enumeração legal e o Tribunal Superior do Trabalho (TST) já sedimentou o entendimento de que a caracterização da insalubridade não depende apenas de perícia, mas exige a classificação da atividade na lista oficial do Ministério de Trabalho e Emprego (OJ-SDI 1-4).

O terceiro problema atine à eliminação do risco de insalubridade decorrente dos nanomateriais, vez que a adoção de equipamentos de proteção individual esbarra também na ausência de certeza sobre os riscos e de estudos sobre o assunto.

Como então equacionar esses problemas e garantir que o trabalhador tenha a sua dignidade respeitada? 
A própria jurisprudência do TST tem lançado uma luz sobre o problema do enquadramento legal, fazendo uma adaptação, na medida em que procura alargar as hipóteses previstas na NR no 15, do MTE. Assim entendeu a Colenda Corte Trabalhista:

RECURSO DE REVISTA. RESPONSABILIDADE SOLIDÁRIA. SUCESSÃO DE EMPREGADORES. 1. Reconhecida a sucessão trabalhista pelo Tribunal Regional, a responsabilidade pelos créditos decorrentes da presente ação é exclusiva da empresa sucessora. Inteligência dos arts. 10 e 448 da CLT. 2. Incidência da Orientação Jurisprudencial 261 da SDI-I/TST, que, não obstante verse especificamente sobre sucessão de bancos, revela o posicionamento desta Corte acerca da responsabilidade em hipótese de sucessão. Precedentes. 3. Óbices da Súmula 333/TST e do art. 896, $\$ 4^{\circ}$, da CLT. ADICIONAL DE INSALUBRIDADE. ATIVIDADE A CÉU ABERTO. EXPOSIÇÁO AO CALOR EXCESSIVO. 1. Na hipótese, $O$ Tribunal Regional manteve a sentença no tocante ao adicional de insalubridade, consignando que "o laudo adotado pelas partes como prova emprestada constatou a presença do agente calor em níveis excessivos em todos os meses do contrato de trabalho da reclamante. Constatou-se, ainda, o enquadramento legal no Anexo 3, da NR-15, da Portaria no 3.214/1978 do Ministério do Trabalho, efetuando as mediçóes do calor conforme determina a norma regulamentar, a qual náo distingue entre calor de ambiente natural ou artificial” e que "o expert menciona que a ré até forneceu equipamentos de proteçáo individual, descritos à fl. 377/378, mas que não sáo suficientes para neutralizar ou eliminar a atividade insalubre no local de trabalho da reclamante, com relaçáo ao calor (fl. 378 , in fine)". 2. Decisáo regional em consonância com a $\mathrm{OJ} 173 \mathrm{da}$ SDI-I/TST, no sentido de que "Tem direito ao adicional de insalubridade o trabalhador que exerce atividade exposto ao calor acima dos limites de tolerância, inclusive em ambiente externo com carga solar, nas condiçóes previstas no Anexo 3 da NR 15 da Portaria no 3214/78 do MTE”. Precedentes. 3. Incidência do art. 896, $\$ 4^{\circ}$, da CLT e aplicaçáo da Súmula 333 desta Corte. INTERVALO INTRAJORNADA. CONCESSÃO PARCIAL. DIREITO AO PAGAMENTO INTEGRAL DE UMA HORA COMO EXTRA. 1. O Tribunal regional deu provimento ao recurso ordinário do reclamante para condenar a segunda reclamada ao pagamento de uma hora diária como extra, tendo em vista a concessão parcial do intervalo intrajornada. 2. Decisão regional em consonância com o item I da Súmula 437/TST ("Após a edição da Lei no 8.923/94, a não concessão ou a concessão parcial do intervalo intrajornada mínimo, para repouso e alimentação, a empregados urbanos e rurais, implica o pagamento total do período correspondente, e não apenas daquele suprimido, com acréscimo de, no mínimo, 50\% sobre o valor da remuneração da hora normal de trabalho (art. 71 da CLT), sem prejuízo do cômputo da efetiva jornada de labor para efeito 
de remuneração"). 3. Incidência do óbice do art. 896, $\$ 4^{\circ}$, da CLT e da Súmula 333/TST. Recurso de revista integralmente não conhecido. ( RR - 795-41.2013.5.09.0562, Relator Ministro: Hugo Carlos Scheuermann, Data de Julgamento: 04/03/2015, 1ª Turma, Data de Publicação: DEJT 13/03/2015, pesquisado em www.tst.jus.br, em 27.03.15, às 09:10 h). (Sem grifos no original).

Todavia, há situações em que essa interpretação alargada não será possível para o caso dos nanomateriais. Quando então o julgador, deve apelar para uma interpretaçáo conforme a Constituição da norma contida no artigo 190, da CLT e, por conseguinte, condizente com a dignidade humana. Esse dispositivo legal tem a seguinte dicção:

"Art. 190 - O Ministério do Trabalho aprovará o quadro das atividades e operações insalubres e adotará normas sobre os critérios de caracterização da insalubridade, os limites de tolerância aos agentes agressivos, meios de proteção e o tempo máximo de exposição do empregado a esses agentes."

A prescrição legal é no sentido de incumbir o MT de aprovar o quadro das atividades e operaçóes insalubres e estabelecer os critérios de caracterização desses agentes. Quando se analisa esse artigo em comento com o artigo 189, da norma consolidada, vê-se que a finalidade desses preceitos é criar um modelo de proteção que respeite a saúde humana. Por outra parte, fazendo-se uma interpretação dos mencionados artigos à luz da Constituição, chega-se à conclusão de que, se valer da omissão legal para não fixar adicional de insalubridade em casos em que as condiçóes de trabalho e a exposição a agentes nocivos causam danos à saúde, é colocar de lado a necessidade de garantir a dignidade humana, consubstanciada como valor constitucional norteador de todo o sistema jurídico.

Convém, ainda, esclarecer que é possível admitir que o enquadramento legal de uma certa atividade como insalubre se dê a partir de normas coletivas (acordos e convençóes coletivas). $\mathrm{O}$ artigo $7^{\circ}$, da Constituição brasileira, reconhece direitos mínimos ao trabalhador, que, pela sua natureza de indispensáveis a um padrão mínimo de proteção, se tornam irrenunciáveis. Contudo, nada impede que tais direitos sejam ampliados pelos acordos e convençóes coletivas de trabalho, cabendo aos sindicatos, portanto, o dever institucional de fomentar estudos técnicos capazes de avaliar os riscos para a saúde do trabalhador que podem decorrer da sua exposição a certos agentes nocivos que não encontram amparo na classificação legal do MTE. O que fica terminantemente proibido e excluído do âmbito de negociação sindical é a possibilidade de redução dos percentuais e índice fixados, porque estes funcionam como um padrão mínimo de proteção legal, que não poderá ser afastado pela vontade das partes, nem mesmo a coletiva, tornando-se, portanto, inderrogáveis. 
Destarte, em termos de nanomateriais a saída para garantir, a priori, uma proteção eficaz ao trabalhador e caracterizar a exposição a esses agentes como insalubre, quando necessário para defender a saúde do trabalhador, é se valer de uma interpretação alargada da classificação legal elaborada pelo MTE; quando isso não for possível, lançar mão de uma interpretação finalística das disposiçóes contidas nos artigos 189 e 190, da CLT, e incentivar a negociação coletiva para que ela produza normas suscetíveis de amparar o trabalhador que lida com a manipulação de nanopartículas.

\subsection{Bases para a Construção de um Marco Regulatório no Brasil}

O tratamento legal dos nanomateriais e, especificamente, da proteção da saúde do trabalhador que lida com esse tipo de substância, esbarra na ausência de certeza científica sobre os riscos decorrentes do uso dessa nova tecnologia. Ademais, a análise desse risco suscita problemas sistémicos. O primeiro deles diz respeito à influência que essa nova tecnologia pode causar na estruturas econômicas e políticas, levantando questóes acerca da cultura e dos valores sociais, notadamente, os que tangem à concepçáo sobre a natureza, as concernentes à política de privacidade sobre o uso desse materiais, e à justiça distributiva. O segundo, toca aos caminhos que a sociedade deverá trilhar para criar estruturas e instituiçóes aptas a avaliar a segurança dessa nova tecnologia. (ELGENMAN; ALDROVANDI; BERGER FILHO, 2013, p. 3).

Essa análise sistémica ganha ainda mais relevo quando se observa que o uso de nanopartículas tem sido cada vez mais frequente, sobretudo, na indústria alimentícia, e que essa utilização ocorre à revelia de qualquer informação para a sociedade. Exemplo disso, ocorre no cotidiano social, nas seguintes situaçóes:

“a) nanopartículas e nanocápsulas que são agregadas aos alimentos e bebidas com o objetivo de mudar seu sabor e a textura (já presentes no mercado, em marcas líderes); b) nanopartículas adicionadas na ração de frangos, com efeitos antibióticos; c) pesticidas, que podem facilmente ser absorvidos por plantas; d) vacinas para tratamento de peixes; e) embalagens de alimentos, com o objetivo de ampliar a validade, controlar variação de temperatura, proteger alimentos contra fungos e bactérias etc. É grande a variedade de materiais utilizados em nanoalimentos. A nanoprata, por exemplo, é muito utilizada por seu efeito antibacteriano. Produtos com nanoprata já estão no mercado: são alimentos, utensílios de cozinha, refrigeradores ou embalagens para guardar alimentos.

Outros materiais podem ser citados: o nano-selênio está sendo utilizado como aditivo que intensifica os efeitos do chá verde; o nanocálcio é objeto de patente que pretende sua utilizaçáo em gomas de mascar. Sais de nanocálcio e nanomagnésio são utilizados como suplementos alimentares; nanotubos do carbono estão sendo desenvolvidos para criação dos mais 
poderosos inseticidas e fungicidas e pesquisadores afirmam a possibilidade de revolução na produção de alimentos e também vegetais para a produção de biocombustíveis."(ELGENMAN; ALDROVANDI; BERGER FILHO, 2013, p. 3).

Ora, da enunciação acima, observa-se que o uso de nanomateriais é algo absolutamente presente no dia a dia da sociedade atual, mas que isso ocorre sem qualquer informação para o destinatário final desses produtos e, sequer, para aqueles que trabalham com esse tipo de tecnologia. Destarte, não se pode negar que esse fato, sozinho, já é suficiente para justificar a necessidade de formular um marco regulatório capaz de contemplar essas questóes sociais.

Portanto, partindo do pressuposto de que o risco pode ser encarado como uma consequência incerta para um dado evento ou atividade a partir de valores humanos, é forçoso concluir que ele envolve uma dimensão social, uma percepção pública e uma avaliação individual de cada ser humano, para que ele seja capaz de determinar se deseja correr tais riscos. Por essa razão, um marco regulatório hábil a propor as bases para uma discussáo jurídica sobre esse tema deverá ser elaborado partindo da análise de três pontos necessários, a saber, a avaliação do risco, a gestão do risco e a comunicação do risco (ELGENMAN; ALDROVANDI; BERGER FILHO, 2013, p. 3).

Esses três pilares essenciais para a elaboração de uma normatização eficiente ganha, ainda, mais relevo quando analisados sob a perspectiva do ambiente de trabalho, porque é o trabalhador quem primeiro entra em contato com as nanopartículas, estando exposto a elas, via de regra, de forma contínua, pelo que se lhe deveassegurar um ambiente laboral no qual se tenha realizado uma avaliação seria dos possíveis riscos, que deverão ser comunicados aos trabalhadores, para que, conjuntamente, empregados, patróes e sindicatos possam implementar mecanismos de gestão aptos a evitá-los.

Ainda, partindo do pressuposto de que o primeiro passo para uma adequada e eficiente regulação legal para o uso de nano partículas no ambiente de trabalho seja a elaboraçáo de uma cuidadosa e detalhada avaliação dos riscos, mister destacar que qualquer tratamento normativo para o problema terá, necessariamente, que fazer uma interface entre o Direito do Trabalho e o Direito Ambiental, de modo que aquele ramo da ciência jurídica se valha de instrumentos jurídicos deste último, tais como o Estudo Prévio de Impacto Ambiental-EPIA (nos casos de empreendimentos causadores de significativa degradação do meio ambiente) e a análise preliminar de risco (APR), para que sejam avaliados os possíveis danos que o uso dessa nova tecnologia pode causar, não apenas para o entorno externo no qual o empreendimento será estabelecido, como também no entorno interno, que diz respeito diretamente aos trabalhadores envolvidos.

É comum, quando se fala em avaliação de riscos ambientais, limitá-la aos riscos que poderão surgir para a flora e a fauna e para a população circundante da regiáo onde 
o empreendimento será estabelecido. Não obstante, não se pode esquecer do ambiente interno e dos danos, sobretudo, à saúde que podem ser gerados nesse ambiente para todos aqueles que se envolvem no processo de produção.

Outro ponto que deverá ser levado em conta na hora de propor uma regulação legal própria toca diretamente na imprescindível necessidade de informação dos trabalhadores que laboram com nanomateriais, visto que são eles que, antes do produto ser lançado no mercado para o grande público, têm contato direto e contínuo com essas partículas, que sequer foram agregadas a outras substâncias. Ou seja, o empregado é aquele que lida continuamente com as nanopartículas na sua versão primária, antes de serem manufaturadas, o que poderá implicar um risco maior para a sua saúde, e ele precisa ter conhecimento dos riscos que esse contato não intermitente pode provocar no seu bem-estar.

Sobre o tema, a Organização Regional Interamericana de Trabalhadores e a Confederação Sindical Internacional, com base no Declaração "Princípios para a Fiscalização de Nanotecnologias e Materiais" (2007), no seu terceiro princípio, denominado "Saúde e Segurança do Público e dos Trabalhadores”, reconhece que:

"Devido ao seu tamanho, as nanopartículas podem atravessar membra-
nas biológicas, células, tecidos e órgáos mais rapidamente do que partí-
culas maiores. Quando inaladas, elas podem ir dos pulmóes à corrente
sanguínea. Há um acúmulo de evidências indicando que os nanoma-
teriais podem penetrar uma pele intacta, principalmente na presença
de surfactantes ou pelo massagear ou flexionar da pele, e ter acesso à
circulação sistêmica. Quando ingeridos, os nanomateriais podem passar
através da parede estomacal à circulação sanguínea. Uma vez na corrente
sanguínea, os nanomateriais podem circular através do corpo e alojar-se
em órgãos e tecidos, incluindo o cérebro, o fígado, o coraçáa, os rins,
o baço, a medula e o sistema nervoso. Uma vez dentro das células, eles
podeminterferir com a funçáo celular normal, causar dano oxidático e
mesmo morte celular." (2007, p. 4).

Ora, são esses riscos que precisam ser avaliados tanto no EPIA, quanto na APR, e, ademais, informados ao trabalhador que precisar expressar, de forma inequívoca, o seu consentimento para se expor a eles.

Um possível marco regulatório sobre os nanomateriais no ambiente de trabalho deve envolver uma gestão conjunta dos prováveis riscos, no que toca à discussão e avaliação de soluçốes capazes de minimizar a exposição do trabalhador e eliminar os prováveis danos. E isso somente será possível com a efetiva participação do trabalhador, do empregador, do sindicato e, nos casos de empresas com mais de 200 (duzentos) empregados, do representantes dos trabalhadores, nos termos propostos no artigo 11, da Constituição brasileira, garantindo sempre que essa prerrogativa de participação se materialize sem retaliaçôes e discriminaçóes para os empregados que participem desse processo. 
Nessa conjuntura, a regulamentação legal deve prever uma nova atribuição para a CIPA das empresas que manufaturem nanomateriais, propondo uma dinâmica que contemple uma hierarquia de controles de exposição - eliminação, substituição, controles de engenharia, abordagens de práticas laborais/gerenciais e equipamentos de proteção pessoal que poderão ser empregados; monitoramento de exposição, vigilância médica e treinamento dos trabalhadores são necessários para assegurar que eles recebam informação mais atualizada sobre as nanopartículas.

Esse envolvimento passa, obrigatoriamente, por uma interlocução das entidades sindicais que deverão assimilar novos papeis sociais e função, não apenas de luta por melhorias salariais, mas de intentar a viabilidade de condiçóes de trabalho adequadas, que, de maneira direta, reflitam em um padrão de vida digna.

Por outras palavras, imperioso é que essa regulação jurídica ponha em relevo a responsabilidade socioambientaldas entidades sindicais. Se elas se tornarem canais de mudança do entorno laboral, exigindo medidas internas de controle e monitoramento dos riscos para o trabalhador, estarâo também contribuindo para a minimização dos danos que esses empreendedores causaráo ao meio ambiente, já que esse controle interno do ambiente de trabalho pode, indiretamente, contribuir para uma adequada eliminação e tratamento de resíduos e substâncias tóxicas que serão lançadas no ambiente externo.

Por último, e a fim de que a necessidade de proteger a saúde do trabalhador se torne real e efetiva, e se destaque essa nova perspectiva de responsabilidade socioambiental das entidades sindicais, mister criar um adicional específico que deverá ser pago aos trabalhadores que lidam com substâncias nanométricas. Contudo, nesse cenário a prioridade não deve ser o pagamento do adicional, que somente se tornará devido quando a adoção de medidas preventivas não forem capazes de eliminar totalmente o risco, mas sim a prevenção de danos à saúde do trabalhador.

\section{Conclusões}

O uso de nanopartículas é uma realidade na sociedade atual, sendo frequente a sua utilização na indústria cosmética, de alimentos e de combustíveis, a fim de dar uma maior eficiência e competitividade aos bens colocados à disposição do consumidor. A preocupação com esse uso indiscriminado reside em dois pontos: o primeiro é que o grande público, seja ele o consumidor, seja ele o trabalhador, toma conhecimento desse uso, o que implica que essa utilização ocorre à revelia dos interessados diretos e indiretos nesse processo produtivo; $\mathrm{O}$ segundo consiste em que se pretende justificar essa falta informação na ausência de estudos científicos sobre esses novos materiais e sobre os riscos que dele poderão advir a longo prazo para saúde humana de forma geral e, em última e mais importante análise, para o meio ambiente. 
A União Europeia tem coligido esforços para criar uma normativa base para o tema, tendo em vista a realidade social de uso acelerado dessas substâncias e a quantidade de recursos patrimoniais que essa nova tecnologia faz circular no âmbito econômico. Todavia, não se trata apenas de uma questão estudada e analisada no espaço europeu sob o viés monetário, porque esses estudos têm levado em conta também a necessidade de informação do consumidor e do trabalhador, de modo que foi criado um subgrupo do grupo de trabalho sobre produtos químicos, criado pelo Comité Consultivo para a Segurança e a Saúde no Local de Trabalho cuja incumbência é preparar um projeto de parecer sobre a avaliação e gestão dos riscos dos nanomateriais no local de trabalho.

No âmbito do direito brasileiro, o assunto tem sido relegado ao esquecimento no que atine à elaboração de uma política legislativa eficiente, seja redefinindo institutos jurídicos a luz da eco tecnologia, seja elaborando uma regulamentação específica para o tema, valendo-se, para tanto, como justificativa do fato de haver uma ideia, náo comprovada cientificamente, de que as nanopartículas trazem mais benefícios do que malefícios para a sociedade.

Independentemente de qualquer certeza científica sobre essa nova realidade, mister se faz que ela se torne presente no cotidiano do ponto de vista de conscientização social, o que impõe uma urgente disseminação de informação sobre o assunto. Ademais, e sob a perspectiva do meio ambiente de trabalho, imperioso é que as entidades sindicais assumam o seu papel de agente ambiental de transformaçáo social, revestindo-se do papel de fomentador de sua responsabilidade socioambiental, que deve ter início com a elaboração de normas coletivas, acordos e convençóes coletivas de trabalho, que efetivamente viabilizem a avaliação, a informação, a gestão compartilhada dos riscos provenientes do uso de substâncias nano e a reinterpretação de institutos jurídicos já existentes no direito interno. Esse novo papel socioambiental dos sindicatos, no entanto, tem que ter como ponto de partida a preocupaçáo com a saúde do trabalhador, mas náo pode se limitar a ela, na medida em que cabe ao sindicatos, partindo do ambiente interno das empresas, propiciar a criação de mecanismos que favoreçam a uma adequada gestão desses riscos também no ambiente externo.

\section{Referências}

ALDROVANDI, Andrea; ENGELMANN, Wilson; BERGER FILHO, Airton Guilherme. Perspectivas para a regulaçáo das nanotecnologias aplicadas a alimentos e biocombustíveis. Disponível em: https://visaemdebate.incqs.fiocruz.br/index.php/ visaemdebate/article/view/69

BOFF, Leonardo. Ecologia, mundialização e espiritualidade. São Paulo: Ática, 1993.

COMISSÃO AO PARLAMENTO EUROPEU, AO CONSELHO E AO COMITÉ ECONÓMICO E SOCIAL EUROPEU Segunda revisão regulamentar relativa 
a «nanomateriais» (Texto relevante para efeitos do EEE), disponível em http:// ec.europa.eu/research/industrial_technologies/pdf/policy/communication-fromthe-commission-second-regulatory-review-on-nanomaterials_pt.pdf

BRASIL. Constituiçáo (1988). Constituição da República Federativa do Brasil: promulgada em 5 de outubro de 1988. Organização do texto: Juarez de Oliveira. 4. ed. São Paulo: Saraiva, 1990.

. Consolidação das leis trabalhistas (CLT). Brasília: Editora do Senado Federal, 2010 .

. Lei Federal No. 6.938 DE 31 DE AGOSTO DE 1981. Já alterada pela Lei no 7804 de 18 de julho de 1989. Dispóe sobre a Política Nacional do Meio Ambiente, seus fins e mecanismos de formulação e aplicação, e dá outras providências.

. RESOLUÇÃO CONAMA no 237, de 19 de dezembro de 1997. Dispóe sobre a revisão e complementação dos procedimentos e critérios utilizados para o licenciamento ambiental. DOU no 247, de 22 de dezembro de 1997.

ENGELMANN, Wilson. A nanotecnologia como uma revoluçáo científica: os direitos humanos e uma (nova) filosofia na ciência.IN: STRECK, Lenio Luiz; MORAIS, José Luis Bolzan de (Org.).Constituição, sistemas sociais e hermenêutica. Anuário do Programa de Pós Graduação em Direito da UNisinos: Mestrado e Doutorado. Porto Alegre: Livraria do Advogado, 2010.

ENGELMANN, Wilson; FLORES, André Stringhi; WEYERMULLER, André Rafael. Nanotecnologias, marcos regulatórios em direito ambiental. Curitiba: Honoris Causa, 2010.

HOHENDORFF, Raquel Von; ENGELMANN, Wilson; OSHIRO, Maria de Lourdes. As nanotecnologias no meio ambiente de trabalho: a precauçáo para equacionar os riscos do trabalhador. Disponível em: http://www.cadernos.prodisa.fiocruz.br/ index.php/cadernos/article/view/114

LEFF, Enrique. Epistemologia ambiental. 5 ed. São Paulo: Cortez, 2002.

LEITE, José Rubens Morato. Introduçáo ao conceito jurídico de meio ambiente. [s.d.t]

LENZ E SILVA, Guilherme Frederico Bernardo; LENZ E SILVA, Lídice Carolina. Saúde e Segurança ocupacional: reflexóes sobre os riscos potenciais e o manuseio seguro dos nanomateriais. Disponível em: https://visaemdebate.incqs.fiocruz.br/ index.php/visaemdebate/article/view/85

ORGANIZAÇÃO REGIONAL INTERAMERICANA DE TRABALHADORES E A CONFEDERAÇÃO SINDICAL INTERNACIONAL. Declaração de Princípios para a Fiscalizaçáo de Nano tecnologias e Materiais. Disponível em: http://www. iiep.org.br/nano/fundacentro/principles.pdf 
UNIÃO EUROPEIA.Conselho da Uniāo Europeia. Diretiva 89/391, de 12 de junho de 1989.

. Parlamento Europeu e do Conselho. Diretiva 2004/37/CE de 29 de abril de 2004.

. Parlamento Europeu e Conselho da União Europeia. Diretiva 1999/92/CE, de 16 de dezembro de 1999.

.Parlamento Europeu e do Conselho. Diretiva 2009/104/CE, de 16 de setembro de 2009.

. Comissão Europeia. Recomendaçáo 2011/696/EU, de 20 de outubro de 2011.

VARELLA, Marcelo Dias; BORGES, Roxana Cardoso Brasileiro. O novo em Direito Ambiental. Belo Horizonte: Del Rey, 1998. 